Mónica Rodríguez-Castro*

\title{
Critical Distinctions between Expert and Novice Translators: Task and Professional Satisfaction
}

\begin{abstract}
The nature of translation projects and tasks in the language industry has undergone significant changes due to a widespread adoption of the subcontracting model and recent technological trends. Managing increasing terminological complexity, higher task specialisation, and higher levels of technical expertise have become essential elements of a translator's professional profile. Nonetheless, the requirement of such a sophisticated professional profile has challenged novice translators in their incipient careers because of limited knowledge and training opportunities. Since many changes have occurred to the profession over a relatively short span of time, this article studies sources of translator satisfaction and dissatisfaction that may affect their perception of work as well as the language industry at large. This study reports results from an ongoing investigation into the 'expertise effect' measured through translator satisfaction in relation to two main categories: (a) professional satisfaction and (b) task satisfaction. A student's $t$-test is used to compare perceptions of novice and expert translators $(\mathrm{N}=250)$, and the results suggest a gap in critical sources of satisfaction between the two populations. The findings could be applied to determine possible means of mitigating career turnover among translators and used by translator trainers to comprehend the needs of novice professionals.
\end{abstract}

\section{Keywords}

task satisfaction; expertise; translator training; professional satisfaction; self-efficacy

\section{Introduction}

Over the last two decades, the language industry (LI) has seen a rapid and widespread adoption of the subcontracting (or outsourcing) model, and this has been complemented by the advent of Internet-related technologies and the emergence of flatter organisational structures (Dunne 2012; Rodríguez-Castro 2015). These trends are interrelated and have subsequently led to new organisational dynamics and a transformation of the work environment (Rodríguez-Castro 2016). Particularly, these trends have (i) reshaped translator jobs in terms of services offered, (ii) changed the tasks that they undertake and, (iii) led to new professional identities in the LI.

In a relatively short span of time, the LI has become a multibillion dollar industry (RodríguezCastro 2016) and the European Union of Associations of Translation Companies (EUATC) has estimated average annual growth rates of 5-7.5\% (Boucau 2006) with estimates of revenues cited to be approximately USD 30 billion (Dunne 2011; Kelly/Stewart 2010) and as high as USD 43 billion in 2017 (De Palma/Stewart/Lommel/Pielmeier 2017). These figures demonstrate the growth and rapid expansion of the industry, which has in turn contributed to drastic changes in the translating process and consequently reshaped the translation profession itself.

As the subcontracting model has become the norm, projectised organisational structures have been more prevalent (Dunne 2012: 143). As clients adopt new decentralised structures, subcontracting translation projects to language service providers (LSPs) has become more common. LSPs have evolved into a 'distributed' network of freelancers and "approximately $90 \%$ of langua-

\footnotetext{
* Monica Rodríguez-Castro

Department of Languages and Culture Studies

UNC Charlotte

E-mail:monica.rodriguez@uncc.edu
} 
ge services are outsourced" (Rodríguez-Castro 2015: 30-31). These new structures not only adopt new methods of Internet-mediated communication but also function from remote work locations with virtual teams. According to Pym et al., 74\% of translators serve as independent contractors or freelancers (2012: 3). Therefore, many LSPs and clients telework and perform tasks in virtual teams. Additionally, as outsourcing becomes more prevalent and provides more employment flexibility, new modalities of multitasking have emerged. In fact, multitasking has become a misnomer that refers to one's ability to perform a wide variety of tasks in the same project (e.g., translation and proofreading) while freelancing full-time or part-time. Hence, today's translators enjoy the flexibility of serving in multiple roles (i.e., translator, editor, proofreader) while performing tasks (i.e., services) for a wider client portfolio.

These trends have also led to an increase in project volume and complexity (Biel/Sosoni 2017). Since translation has predominately evolved into a mass-production industry, the translation process along with the nature of tasks and roles has drastically changed. Particularly in the case of freelancers, an increased division of labour, specialisation of skills and the systematic reuse of language resources have become crucial in order to handle complexity in larger projects (Garcia 2009). A higher level of technical expertise and diversified professional profile (EhrensbergerDow/Massey 2014b) has become necessary for the labour force to undertake new tasks and projects. Today's LI not only demands a constant execution of heterogeneous tasks for translators, but an evolving skillset becomes critical in order to remain competitive.

These trends in projectised organisational structures have not only accentuated task complexity and project volume, but have arguably reshaped a translator's professional profile. The translator's professional profile has become increasingly characterised by a widely varied and technically sophisticated skillset, and essentially more dynamic. Since the labour force is in a constant flux and has to strive to remain competitive, this has resulted in higher degrees of task dissatisfaction, particularly for professionals in their incipient careers. Newcomers entering the language industry with limited training and knowledge are struggling to rapidly develop skills while increasing their productivity to meet the continuous pressures of the growing translation services market.

Unlike other professions, the language industry is volatile and continues to remain "almost totally unregulated" (Katan 2009: 113). Translators' sources of professional satisfaction remain scarce due to the lack of public recognition or occupational prestige. The social perception of the translation profession is monolithic, i.e., it does not account for the dynamic and specialised nature of the profession and enjoys a relatively low status (Dam/Zethsen 2008, 2010; Chesterman/ Wagner 2002). The fact that translation can be viewed as a commodity has worsened its professional status or recognition, since price often gets prioritised over quality. More importantly, there is no organised career structure in the profession (Katan 2009: 123-124), and enhancing one's professional profile and skillset can be challenging under the freelancing model. The literature on translation studies cites professional recognition and prestige as the most common intrinsic sources of satisfaction among translators, and "their 'professionality' lies in their individually honed competencies in the field" (Katan 2009: 111). As a nascent and evolving industry, multiple aspects of the translation profession can affect the level of satisfaction that translators perceive. These sources of satisfaction and dissatisfaction affect translators' perception toward the profession and may reshape their professional identity. Consequently, in an industry that depends largely on its human capital, it is crucial to address prevalent sources of dissatisfaction in order to avoid potential career turnovers.

Language professionals are faced with many challenges such as a need to quickly adjust to new trends in the profession, or increasingly enhance the professional profile to be able to offer a diversified service portfolio. These challenges can only be overcome by a highly qualified and specialised labour force, and could potentially be perceived as insurmountable by novices in the absence of a structured training environment. Thus, an increasing gap in translator (dis)satisfaction is expected to emerge between novice and expert translators under the outsourcing model. This emerging gap calls for research that attempts to comprehend crucial sources of satisfaction 
and dissatisfaction between these two indispensable groups of the labour force. This study aims at identifying a potential 'expertise effect' in most prevalent aspects associated with a translator's role(s). Specifically, professional and task satisfaction are assessed to determine major distinctions, if any, between the two groups of study so as to comprehend means of mitigating early career turnover among novice translators and eventually enhancing translator training approaches.

\section{The 'expertise effect' in Translation Studies}

This study seeks to investigate components associated with translator professional and task satisfaction, drawing specific attention to the differences between expert and novice translators. In the literature on translation studies, some authors have used translation competence and translation expertise as near synonyms (Muñoz Martín 2014: 6; Ehrensberger-Dow and Massey 2014a: 63), and the literature on translation process research (TPR) and expertise studies has recently defined the 'expertise effect' as a "comprehensive framework that allows for including a wide variety of task-related cognitive resources, detailing how they interact, and then describing how those resources [...] change during the acquisition of expertise." (Shreve/Angelone/Lacruz 2018: 47) Additionally, Shreve (2006) argues the need of declarative and procedural knowledge from a variety of cognitive domains in conjunction with training and experience (28), but insists on hours of deliberate practice, exposure to more varied tasks, and consistent superior performance so that metacognitive knowledge and regulation can be progressively developed until translation expertise emerges (Shreve 2009; Shreve/Angelone 2010). Muñoz Martín (2009) concurs that translation expertise includes "extensive domain knowledge, but crucially also heuristic rules that simplify and improve approaches to problem solving, meta knowledge and metacognition" (25; see also Sirén/Hakkrarainen 2002). Within the expertise framework, this concept acknowledges the existence of a variety of skill levels, and also entails the notion of progressive development or evolution in the translator's acquisition history in five stages, ranging from (1) novice, (2) advanced beginner, (3) competent, (4) proficient, to (5) expert (Shreve/Angelone/Lacruz 2018: 47; Woll 2001: 283). Thus, the 'expertise effect' is 'often taken to correlate with the time spent in such [deliberate] practice (Muñoz Martín 2014: 5) or in terms of translation productivity in 'full time equivalents' (FTE) of individual translation activity in a full-time work schedule per year (European Union 2006:c 284/15). Although this range of experience is debatable, it allows us to measure exposure to translation activity and establish major distinctions among groups with significantly different degrees of experience. Therefore, in this article, the term 'expert' is used to refer to professional translators with a minimum of ten years of professional experience (also quantified as FTE), and expertise is assessed in the study through the translator's professional profile.

Due to the multiplicity of roles that translators play in the work environment, these roles define the main characteristics of their professional profiles. A translator's professional profile is increasingly sophisticated due to the fact that technical translation has continued to account for approximately $90 \%$ of the translation output per year worldwide (Kingscott 2002: 247). Given that scenario, the professional profile identified in this study includes years of experience in the LI, formal education (in translation studies or related disciplines), industry certifications, and specialisation (or subject matter expertise) as well as technical expertise. Typically, specialised or technical translation requires (a) a higher level of subject matter expertise, (b) comprehension of terminological complexity and (c) higher level of technical knowledge (Byrne 2006). Expert translators feel more confident about handling high volume and tight deadlines while meeting quality expectations. Jääskeläinen also highlights an expert's capability to process larger chunks of text and automation of multiple linguistic tasks (2010: 219-222). Concerning segmentation, Dragsted adds that the sentence was not originally a central unit in translator's mental processing. However, with the implementation of translation memories (TM), novices (non-professionals) tend to prioritise segmentation at the sentence-level and perceive that they are benefiting from TM. By contrast, professionals rather focus on clauses or phrases and acknowledge that working at the sentence level complicates their translating process (Dragsted 2005; Dragsted 2006). In comparison 
to experts, novices may "rarely deal with large-scale translation projects" (Gouadec 2007: 27). Novices may not feel confident with subject matter expertise, may be intimidated by terminological complexity, and may lack technical expertise. Kruger/Dunning posit that novices often manifest a feeling of overconfidence in task completion due to "the double curse of being unskilled and unaware that induces the unskilled to dramatically overestimate their expertise" (1999: 726). Hence, the literature on the 'expertise effect' has been used to determine crucial distinctions in the level of satisfaction between experts and novices vis-à-vis the aspects associated with (a) translation-related tasks and (b) the translation profession as described in the next section.

\section{Operationalising Translator Satisfaction}

This section describes the concepts of translator satisfaction while focusing on two broad categories: (a) professional satisfaction and (b) task satisfaction. The concepts in this study have been adopted from the literature in Occupational and Organisational Psychology as well as Organisational Behaviour, and have provided a framework to establish a unique distinction in the construct of translator satisfaction between extrinsic and intrinsic sources of satisfaction. Extrinsic sources of satisfaction or profession-related aspects are captured in the study under professional satisfaction, whereas intrinsic sources of satisfaction refer to a positive feeling that derives from the task or work itself, and are investigated as elements of task satisfaction in this study. This is a unique distinction that has generally been ignored in the literature of Translation Studies where both task-related and profession-related aspects have typically being studied under the label of 'job satisfaction.'

\subsection{Professional Satisfaction}

Professional satisfaction is operationally defined as the feelings of status or achievement that an individual develops from a desired level of competency and allows for growth, career path optimization and professional recognition (Chen 2008: 106-107). Professional satisfaction evolves from the sense of identity as a member of an occupational community of language professionals playing similar roles in the industry, and includes external sources of satisfaction that derive from belonging to the translation profession. This study assesses translators' views of the profession and their perceived role in the LI, specifically such crucial components of professional satisfaction as professional self-concept, professional reputation, career commitment and turnover.

The relationship between professional satisfaction and professional self-concept or professional identity has drawn limited attention in translation studies. The professional self-concept is defined as the set of attributes, beliefs, values and experiences by which individuals define themselves in their professional lives (Ibarra 1999; Muñoz Martín 2014). The literature in Organisational and Occupational Psychology has long studied that changes in a person's role and tasks lead to changes in one's professional identity. Katan (2009) states that translators can be viewed as "dedicated and mainly satisfied wordsmiths, who take pride in their job" (111), but are also known as intercultural communication experts (Holz-Mänttäri 1984) and "agents of social change" (Tymoczko/Ireland 2003). In particular, "freelancers see themselves as dynamic, business-like people. Choosing to be self-employed gives them professional' status" (Gouadec 2007: 169). Furthermore, it can be argued that translators possess a strong sense of professional pride, but their professional self-concept may not be homogenous. Person-environment fit theory posits that individuals show a higher level of satisfaction vis-à-vis the self-concept when their role is compatible with individual needs and abilities (Kaplan 1983). Translators broadly view themselves at the very end of the food chain, and may not feel that they play a role in the industry, particularly novice translators. For instance, translators who feel their roles and tasks do not meet their career expectations show lower levels of satisfaction with the profession.

Additionally, the professional self-concept can be understood through society's views about translators. In this case, the general social perception is that translators are individuals capable of 
communicating in at least two languages. There is generally a lack of recognition of a comprehensive skillset and specialised training, even though it may vary from country to country. In North America, Canada was the first country to recognize the translation profession. The U.S., Canada and Mexico recognized translation as a distinct industrial sector in 1997 and the European Union (EU) in 2008 (Dunne 2011). Despite language professionals being recognized in renowned institutions like the UN and the EU, low professional recognition and 'very low status is accredited to translators worldwide' (Katan 2009: 111; Dam/Zethsen 2008). Low status may be intrinsically associated with feelings of lack of professional appreciation. Albeit translators value the role of associations in promoting professional recognition, employers do not equally acknowledge these efforts (Dam/Zethsen 2008) as 'certified' status is not highly sought after by employers (Bowker 2005: 19). The lack of occupational recognition could lead to dissatisfaction with the social recognition of the translation profession, this is typically relevant to non-literary translators.

As an additional source of professional satisfaction, career commitment, professional commitment and career development have been used interchangeably in the literature. Mayer/Salovey (1993) were forerunners in investigating that the level of an individual's participation in an occupation might significantly vary with the level of priority given to professional involvement. In fact, high levels of career satisfaction are associated with active participation in professional meetings and gatherings. Individuals who have a strong commitment may not be involved in occupational activities but continue with membership (Mayer/Salovery 1993). Lacking professional commitment has been found to be associated with an intention to leave the profession (Hall/ Smith/Langfield (2005). Career development helps a person to acquire current knowledge, upgrade skills, and contribute to the profession. For instance, novice translators may be interested in attending conferences to learn or pursue certifications, but it may not be feasible due to budgetary and time constraints, especially due to limited organisational support. Conversely, experts may lead workshops, present at conferences or provide consulting services (McKay 2006), all instances of undertaking a leadership role in career commitment that typically results in higher levels of satisfaction. Due to the emerging need to possess a highly sophisticated skillset to remain competitive, career involvement exemplifies a crucial source of professional satisfaction in the LI.

Notwithstanding the constraints of the outsourcing model vis-à-vis career commitment, coaching and mentoring have been suggested as motivational approaches to promote retention policies for 'knowledge' industries. Particularly, Mortensen et al. (2002: 1452) conducted a comprehensive study of 2,600 participants and selected being mentored, serving as a mentor, and selfassessed high professional involvement among key aspects of professional satisfaction. Burke (2001) and Burke/McKeen (1995) focused on the motivators of professional satisfaction of managerial and professional women and found that training, career development, and undertaking challenging tasks were the main contributors to high levels of professional satisfaction in the early stages of their careers. Therefore, alternative virtual coaching, mentoring and other mechanisms can be considered for the development of the talent pool in the LI to promote career development among freelancers.

The concept of professional reputation and professional prestige (Dam/Zethsen 2008, Dam/ Zethsen 2010) are intrinsically related and used interchangeably in this study. Professional reputation depicts the visibility or public image from the society's assessment of the specific characteristics or reputation of an individual, along with the prestige or perception of the significance of one's work related to personal and social esteem (Stamps 1997). This concept reflects a perception that others value the translator's services and skillset. Broadly speaking, there is a "lack of awareness in society about what constitutes translation competence and its complexity as well as lack of recognition of the importance of translation." (Dam/Zethsen 2010: 205) As translation "does not range as a proper profession" (Dam/Zethsen 2010: 205) and is not regulated, its labour force neither enjoys high visibility nor occupational prestige (or fame); thereby, professional reputation in the LI may derive from the translator's branding recognition (McKay 2006) or a history of the successful completion of prestigious projects from Fortune 500 clients. As a translator's 
client portfolio increases, it leads to increasing workload, new occupational opportunities and long-term business relationships with clients, which in turn result in career satisfaction. Broadly speaking, translators feel a special pride when a long-term client needs a translation service or when they are referred by a client, since it implies increasing professional recognition. As recognition increases, a translator can see financial benefits, occupational flexibility, and an ability to choose clients and projects; thus increasing the level of professional recognition that can positively impact professional satisfaction.

The factors of professional self-concept, reputation and career commitment can arguably be crucial sources of professional satisfaction (Chen/Chang/Yeh 2004; Burke 2001; Ibarra 1999). The level of professional satisfaction is expected to vary with expertise, with experts probably having a more positive attitude toward their career and to the profession. Experts may feel that they play an essential role in the industry by being more actively involved in associations, by producing publications, leading workshops or serving as mentors, resulting in higher levels of satisfaction toward career involvement and a more fulfilled professional self-concept. Conversely, the literature identifies career turnover as an indirect measurement of professional dissatisfaction. Work behaviour outcomes have been widely investigated by expectancy-value approaches, these studies suggest that a negative self-concept contributes to high career turnover rates and indicates dissatisfaction with the career path and the profession (Tett/Meyer 1993). In the LI, career turnover is likely to be higher among novices while experts are more likely to stay in the profession for such reasons as a feeling of 'investment' and a shortened window of opportunity to change careers (Kyndt et al. 2009). The concept of turnover is crucial in this study since one's decision to leave the profession - not just the job - may arise from any of the aforementioned sources of professional dissatisfaction.

\subsection{Task Satisfaction}

Task satisfaction is "a psychological construct that is associated with individual perceptions of the specific tasks that compose the work associated with a role" (Rodríguez-Castro 2016: 32). In order to comprehend translator task satisfaction, this study focuses on the concepts of self-efficacy (including task scope and task description) and task self-fulfilment (see, e.g., Rodríguez-Castro 2016 for a more comprehensive review on task satisfaction). The concept describes a feeling of success associated with such intrinsic motivators as growth, recognition and enrichment from the work itself (Herzberg 2003: 92-93). Mason and Griffin (2002: 299) studied the relationship between task-specific factors (familiarity, challenge, variety) with procedural skills and concluded that it enhances task satisfaction. In this study, the level of satisfaction toward tasks (namely translating, proofreading, terminology management, etc.) is likely to increase as the feeling of knowing (FOK) increases. FOK is a metacognitive phenomenon that arguably assesses task satisfaction (Koriat 1993) and is intrinsically related to the concept of self-efficacy. Self-efficacy is one's ability to evaluate the success or failure associated with the task being performed (Bandura 1995). Self-efficacy encompasses the self-concept sub-dimension that belongs to the translation expertise construct (Muñoz Martín 2014: 33), and is therefore intrinsically related to 'expertise effect.' As a translator's translation expertise evolves, additional metacognitive knowledge and cues are available for complex problem solving and recognition of successful task completion (Shreve 2002: 162). Translation expertise allows translators to develop task awareness, including a growing understanding of task scope and the task description that determines the complexity of the work itself.

Experts are likely to have greater task awareness, i.e. a better understanding of task scope (range of discrete activities included in projects) and task description (deadline, client specifications). Expert translators who have established their reputation in a specific domain are generally offered larger projects (i.e. higher volume, higher income, constant stream of work) and often enjoy the challenge of undertaking such projects with higher terminological and technical complexity. Since autonomy is a function of years of experience, experts are also granted higher levels of free- 
dom and allowed to take more initiatives (Katan 2009). Unlike experts, novices are likely to feel overwhelmed by terminological complexity, tight deadlines, and implementation of CAT tools, and may not be ready to wear multiple hats. In fact, novices often fail to recognize translation problems and interferences (Biel 2011); task complexity may be perceived as demotivating because they fail to understand scope, project timeline and overall quality expectations.

In addition to such intrinsic sources of task satisfaction as self-efficacy, successful task completion in multiple projects can lead to further intrinsic motivators such as task pride and task self-fulfillment. The literature on self-fulfillment posits that individuals exhibit a positive attitude when their professional and personal needs are aligned (Greene/Burke 2007). Self-fulfilment is defined as "a pleasurable or positive emotional state resulting from the appraisal of one's job or job experiences" (Mason/Griffin 2005). In this study, the importance of this concept is twofold: translators are broadly known to take strong pride from performed tasks (Katan 2009), and their dedication to life-long learning is typically attributed to the intrinsic nature of all language professionals (Durban 2010). Furthermore, the motivation for achievement is identified as the strength of a translator's desire to excel, to succeed in difficult tasks, and to do better than the competition. According to Herzberg (2003), successful completion of a task and seeking solutions to complex problems are examples of occupation enrichment (94-96). High-need achievers constantly seek success, and task challenges, thereby gaining intrinsic motivation from project completion, especially challenging projects with highly technical inputs and outputs or projects with tight deadlines. Hence, regarding self-fulfilment, both experts and novices may take a strong pride in their work and satisfaction from "the feeling of translating" (Dam/Zethsen 2016: 181). However, the level of task satisfaction could be relatively higher in the case of experts since they have a longer occupational history. This may lead to higher intrinsic motivation from multiple successful completions, outstanding offers as well as gestures of performance appraisal.

\section{Methodological Approach}

The concepts discussed in Section 3 have been used for the assessment of professional and task satisfaction among expert and novice translators. An online questionnaire was designed as the instrument for data collection, consisting of a task satisfaction index as well as a professional satisfaction index (Rodríguez-Castro 2015). Instrument reliability was measured by using Cronbach's alpha coefficient ( 0.98 out of 1 ), and data collection was conducted online during ca. two months. The data are further analysed by using a parametric test that is performed by applying an independent-samples student's $t$-test in order to statistically compare the two populations (Hale/Napier 2013). The results of the two-tailed $t$-test are used to determine whether novices and experts exhibit significantly different levels of satisfaction from task-related or profession-related aspects.

\subsection{Participants}

A total of 250 participants completed a multifaceted questionnaire that included questions on specific aspects of task and professional satisfaction. Professional translators were recruited to participate in the study based on professional experience in the LI or productivity in total FTEs (full time schedule per year, average of 8 hours per day). Their answers to the questionnaire included their role in the LI, commonly performed tasks, and types of services provided. Participants belonged to a wide variety of areas of specialisation (e.g., scientific, legal, health care, business, information technologies), educational background and technical expertise (i.e. implementation of translation and localisation tools, terminological management tools, corpora, etc.) and represented more than ten countries and languages (e.g., Argentina, Chile, Germany, Iran, Japan, Mexico, Spain, UK, United States). Years of experience has been chosen as the threshold for the expert versus novice differentiation; however, it may be noted that, for the sake of brevity, translators with 3-10 years of experience are not included in this study since extreme groups are more suitable to investigate the distinctions between experts and novices. Experts in this study are iden- 
tified as active language professionals with more than ten years of occupational experience or at least 10,000 hours of full-time work (Muñoz Martín 2014: 5; Shreve 2006: 29), while novices are identified as professionals with less than three years of experience. Based on sample sizes commonly cited in previous questionnaire studies that range between 40s (Pan 2014) to upper 200s (Kyndt et al. 2009), the sample size for the study is considered to be adequate for performing hypothesis testing. It may be noted that out of the 250 participants, 86 respondents were classified as experts while 117 respondents were classified as novices. The remaining 47 respondents had an experience of more than three years but less than ten years. The classification of novices and experts is arguably rigid and may not capture nuances of different degrees of experience, however existing operationalisation in the literature supports this classification (Shreve/Angelone/Lacruz 2018; Shreve 2006; Muñoz Martín 2014).

\subsection{Overview of Questionnaire}

The reliability of the instrument was tested before starting data collection, and the instrument did not demonstrate any inherent deficiencies that could compromise the data collected from the instrument (Rodríguez-Castro 2015). The instrument was also tested for readability in a pilot phase at the American Translators Association's annual conference (2010) and it was also ensured that the participant's responses would remain anonymous. The readability tests ensured that sentence length, syllables and word lengths were appropriate. Only terminology commonly used in the industry was used, and all possible efforts were made to ensure semantic transparency. FleschKincaid Grade Level Index was used to identify problematic statements that were subsequently revised as part of pilot phase completion. Participants were preliminarily asked about their professional identity and the relationship between specific elements of the professional profile with deadlines (i.e., subject matter and technical expertise). The questionnaire on satisfaction consisted of two sets of questions. The first set included sources of professional satisfaction (Appendix 1) and the second set contained statements concerning sources of task satisfaction (Appendix 2). A quantitative approach has been chosen in this study by using a five-point Likert scale (1-5) that ranges from 1 (very satisfied/highly agree) to 5 (very dissatisfied/highly disagree). In order to reach a broad audience of active professional translators, the questionnaire was distributed online through multiple means of communication (email lists, translation portals, etc.). This effort resulted in participation from wide-ranging specialisations and languages with a variety of job profiles and professional experiences. It may be noted that this study does not account for crosscultural or geographical differences among participants that may be interesting but are outside the scope of this article.

\subsection{Data Analysis}

Data collected from the online questionnaire has been analysed by using an independent samples Student's $t$-test (also called $t$-test) to compare the responses between novices and experts in order to comprehend differences, if any, in their perceptions toward levels of satisfaction. The $t$-test is widely used in applied linguistics to compare data (Dörnyei 2007) and has been applied to translation studies (Mellinger/Hanson 2017: 87). The $t$-test allows this study to determine statistically significant differences between the two groups whose means are assumed to be normally distributed. For this test, the null hypothesis $\left(\mathrm{H}_{0}\right)$ is that the mean values from both populations are identical, whereas the alternate hypothesis $\left(\mathrm{H}_{1}\right)$ is that the responses are statistically distinct (Mellinger/ Hanson 2017: 88-91). The data analysis toolbox in Microsoft Excel has been used for analysis, this toolbox reports the significance level for $\mathrm{H}_{0}$ expressed as the $p$ value in the tables. As a result, the significance level for $\mathrm{H}_{1}$ is reported as 1-p. An overview of the quantitative results is given in Sections 5.1. and 5.2. In addition, the effect size for each $t$-test was calculated by Cohen's $d$. 


\section{Results}

Table 1 and Table 2 display the descriptive statistics results to compare the perceptions of experts and novices toward aspects of professional and task satisfaction. Both tables list the mean and standard deviation (SD) in conjunction with the results from the $t$-test ( $t$ and $p$ values).

\subsection{Questionnaire Items - Professional satisfaction}

Results from the professional satisfaction questionnaire are compiled in Table 1 and discussed in this section. In terms of the professional self-concept, differences between the two groups are significant and experts exhibit a significantly higher level of satisfaction with their perceived role in the industry $(p=0.001)$ and their occupational status in meeting their professional expectations $(p=0.001)$. The data yielded non-significant differences between the two groups with regards to social recognition (Table $1, p=0.17$ ) and professional identification ( $p=0.87$, Table 1$)$.

Additionally, novices and experts differ on their satisfaction levels of professional appreciation. Novices do not feel as professionally appreciated as experts in the current LI $(p=0.05)$. Novices acknowledge the need for updating their skillset and express dissatisfaction with the opportunities to engage themselves in career development $(p=0.04)$, and schedule constraints that do not allow for career development opportunities $(p=0.06)$, as argued in the literature.

\begin{tabular}{|c|c|c|c|c|c|c|c|}
\hline \multirow[t]{2}{*}{ Item } & \multirow[b]{2}{*}{ Mean } & \multicolumn{2}{|c|}{ Expert } & \multicolumn{2}{|c|}{ Novice } & \multirow[t]{2}{*}{$t$} & \multirow[t]{2}{*}{$p$} \\
\hline & & SD & & SD & & & \\
\hline \multirow{6}{*}{ 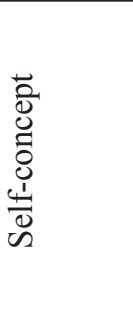 } & Professional identification & 1.87 & 1.14 & 1.83 & 0.90 & 0.25 & 0.87 \\
\hline & Feeling professionally appreciated & 1.76 & 1.22 & 1.78 & 1.13 & 0.05 & 0.05 \\
\hline & Occupational status meeting your & 1.70 & 0.95 & 2.59 & 1.14 & 2.65 & 0.001 \\
\hline & expectations & & & & & & \\
\hline & My role in the industry & 1.67 & 0.75 & 2.24 & 0.87 & 2.65 & 0.001 \\
\hline & Social recognition & 2.87 & 1.25 & 2.93 & 1.45 & 0.19 & 0.17 \\
\hline \multirow{9}{*}{ 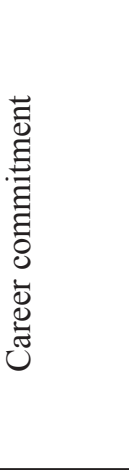 } & Industry certifications & 1.63 & 0.49 & 1.90 & 0.72 & 1.78 & 0.07 \\
\hline & Need to update my skills & 2.34 & 0.97 & 1.94 & 0.87 & 1.91 & 0.06 \\
\hline & Career development opportunities & 2.57 & 1.25 & 2.00 & 0.94 & 2.12 & 0.04 \\
\hline & Schedule allowing for career development & 2.48 & 1.17 & 1.91 & 0.72 & 2.00 & 0.06 \\
\hline & Attending conferences & 1.36 & 0.49 & 1.39 & 0.49 & 0.21 & 0.83 \\
\hline & Presenting at conference & 1.76 & 0.42 & 1.86 & 0.33 & 1.10 & 0.27 \\
\hline & Presenting workshops or training sessions & 1.70 & 0.46 & 1.84 & 0.36 & 1.47 & 0.14 \\
\hline & Current memberships & 2.03 & 1.17 & 2.71 & 0.95 & 1.62 & 0.11 \\
\hline & Mentoring as helpful for my career & 2.56 & 1.13 & 1.80 & 0.78 & 3.32 & 0.001 \\
\hline \multirow{5}{*}{ 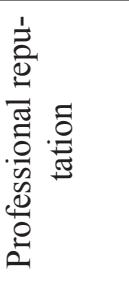 } & Receiving a project from a long-term client & 1.37 & 0.56 & 1.72 & 0.81 & 2.24 & 0.03 \\
\hline & Having prestigious projects & 2.23 & 0.77 & 2.26 & 0.97 & 0.14 & 0.90 \\
\hline & Financial benefits from branding recognition & 1.77 & 0.89 & 2.15 & 0.92 & 1.81 & 0.07 \\
\hline & I can afford to choose with whom I work & 1.68 & 0.82 & 2.54 & 1.30 & 3.64 & 0.001 \\
\hline & Flexibility to accept and reject projects & 1.67 & 0.95 & 2.24 & 1.20 & 2.30 & 0.08 \\
\hline \multirow{2}{*}{ 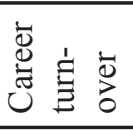 } & Leaving the profession & 2.10 & 0.30 & 2.07 & 0.49 & 0.38 & 0.70 \\
\hline & Probability of finding a new job & 2.83 & 1.58 & 2.37 & 0.97 & 1.44 & 0.16 \\
\hline
\end{tabular}

Table 1. Questionnaire: Professional satisfaction - Expert vs. novice comparison. 
More precisely, the test did not identify significant differences between the two groups in terms of satisfaction with opportunities to present at conferences $(p=0.27$, Table 1$)$, leading training sessions or workshops $(p=0.14)$ and attending conferences as a kind of career commitment $(p$ $=0.83)$, albeit experts manifest relatively higher levels of satisfaction $(M=1.76, M=1.70, M=$ $1.36)$, respectively) than novices. The data showed non-significant differences between the two groups with memberships $(p=0.11)$ and certifications $(p=0.07)$.

Lastly, concerning the benefits of mentoring in career development, novices seem to be highly satisfied with the positive impact of mentorship $(t=3.32, p=0.001)$ compared with experts. This indicates that mentoring is the strongest source of satisfaction among novices in the category of career commitment followed by career development opportunities.

Professional reputation is a source of professional satisfaction that novice translators may lack due to their emerging careers. As argued in the literature, having the occupational flexibility of working with providers/clients of individual choice $(p=0.001)$ and receiving new projects from long-term business relationships $(p=0.03)$ are crucial sources of professional satisfaction that only experts experience.

The test does not identify significant differences between the two groups in terms of satisfaction with being able to accept and reject projects $(p=0.08)$, the financial benefits from their branding recognition $(p=0.07)$ along with receiving projects from Fortune 500 companies $(p=0.90)$. Furthermore, while novices show dissatisfaction with having prestigious projects $(M=2.26)$, experts show higher levels of satisfaction with financial benefits $(M=1.77)$ and the flexibility to accept and reject projects $(M=1.67)$ that novices may not enjoy.

To conclude the results from professional satisfaction, respondents were asked about possibility of leaving the profession and finding a new job, as possible signs of professional dissatisfaction. The data shows non-significant differences suggesting that both groups could leave the profession and experts do not differ from novices in potential career turnover $(p=0.70)$.

\subsection{Questionnaire Items - Task satisfaction}

Results for the task satisfaction questionnaire are summarized in Table 2. Prior to being asked about specific sources of task satisfaction, participants were asked about deadlines, the contribution of CAT tools in expediting the translating process, significance of subject matter expertise in meeting deadlines, and perceptions of quality/time trade-offs.

\begin{tabular}{|c|c|c|c|c|c|c|c|}
\hline \multirow[t]{2}{*}{ Item } & \multirow[b]{2}{*}{ Mean } & \multicolumn{2}{|c|}{ Expert } & \multicolumn{2}{|c|}{ Novice } & \multirow[t]{2}{*}{$t$} & \multirow[t]{2}{*}{$p$} \\
\hline & & SD & Mean & SD & & & \\
\hline \multirow{9}{*}{ 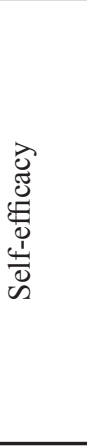 } & My subject matter expertise helps me with deadlines & 1.50 & 0.72 & 1.90 & 0.91 & 2.21 & 0.03 \\
\hline & CAT tools are essential to meet deadlines & 2.87 & 1.62 & 2.70 & 1.50 & 0.49 & 0.62 \\
\hline & Deadlines do not compromise quality & 2.78 & 1.34 & 3.32 & 1.32 & 1.79 & 0.08 \\
\hline & Your own understanding of task scope & 1.44 & 0.56 & 1.84 & 0.92 & 2.49 & 0.001 \\
\hline & Clarity of task description & 1.70 & 0.83 & 2.13 & 0.99 & 2.16 & 0.03 \\
\hline & Types of tasks involved & 1.44 & 0.61 & 1.67 & 0.67 & 1.64 & 0.10 \\
\hline & Level of terminological complexity & 2.74 & 1.19 & 3.63 & 1.24 & 3.15 & 0.001 \\
\hline & Working on complex tasks & 1.58 & 0.89 & 1.56 & 0.64 & 0.11 & 0.91 \\
\hline & Autonomy allowed in tasks & 1.56 & 0.79 & 2.23 & 1.11 & 3.28 & 0.001 \\
\hline \multirow{3}{*}{ 壳 $\frac{\vec{\Xi}}{\stackrel{\Xi}{\Xi}}$} & Successful project completion & 1.65 & 0.93 & 1.40 & 0.69 & 1.32 & 0.18 \\
\hline & Outstanding offers & 2.38 & 1.21 & 2.06 & 0.98 & 1.24 & 0.22 \\
\hline & Project manager/client shows appreciation & 2.17 & 1.02 & 2.61 & 1.27 & 1.66 & 0.10 \\
\hline
\end{tabular}

Table 2. Questionnaire: Task satisfaction - Expert vs. novice comparison. 
As expected, experts acknowledge that deadlines do not affect quality $(M=2.78, S D=1.34$, Table 2 ) and CAT tools are essential to meet deadlines $(M=2.87, S D=1.62$, Table 2). The data shows significant disagreements between both groups regarding the necessity of subject matter expertise in order to translate faster and meet tight deadlines $(p=0.03)$.

The results support the claim that advanced self-efficacy enhances experts' understanding of task scope $(p=0.001)$ as perceived in much higher levels of satisfaction vis-à-vis task scope among experts. In addition to task scope, this section also considers the results of the questionnaire in relation to such self-efficacy-related sources of satisfaction as task complexity and terminological complexity. Unlike novices, experts are highly satisfied with the level of terminological complexity observed in projects $(p=0.001)$ and with task autonomy $(p=0.001)$ with a medium effect size $(d=0.69)$. In terms of descriptions showing the accurate nature of the tasks, significant differences are reported between novices and experts $(p=0.03$, Table 2$)$ suggesting that novices rely on clear details from task descriptions in order to understand task requirements and the nature of the work that needs to be completed.

Non-significant differences are reported between the two groups regarding the level of satisfaction with complexity undertaken in tasks, specific types of tasks involved, and deadlines not compromising quality. However, it may be noted that novices are slightly more dissatisfied with lack of variety in tasks $(M=1.67)$, possibly due to the lack of flexibility or choices in selecting tasks, and expressed their belief that deadlines actually compromise quality $(M=3.32)$.

Lastly, the results suggest non-significant differences between experts and novices vis-à-vis the concept of self-fulfilment. Novices' responses demonstrate somewhat higher levels of satisfaction toward outstanding offers $(M=2.06)$ and well-done completed tasks that may bring more work $(M=1.40)$, suggesting that experts do not rely on having outstanding offers or completing a complex project successfully as intrinsic sources of motivation. Unlike novices, experts feel slightly higher levels of self-fulfilment from a nice word on performance from the client or project manager $(M=2.17)$ with a medium effect size $(d=0.31)$. Overall, the results identify terminology management, understanding of task scope, and autonomy allowed in tasks as the most significant sources of task dissatisfaction among novices.

\section{Discussion and Conclusions}

The results of this study suggest that there are some significant differences in the sources and levels of professional and task satisfaction among translators. Emerging trends have resulted in challenging working conditions for translators, particularly for new professionals starting in the translation industry as freelancers. Results indicate that even though novices strongly identify with the LI, they are not satisfied with their occupational status and are strongly considering a change of career. However, experts enjoy occupational flexibility resulting from freelancing due to their professional recognition.

A translator's professional profile has become complex, typically requiring a high level of subject matter expertise and terminology management skills. Experts have benefited from these trends due to high levels of self-efficacy. This has allowed experts to have greater autonomy in decision making, resulting in higher task satisfaction. However, these aspects are seen to lead to dissatisfaction among novices. It could be argued that experts will always have a higher level of professional satisfaction due to their experience; however, the same cannot be expected about task satisfaction. The relatively lower level of task satisfaction among novices accentuates potential challenges for the industry as Internet-related technologies increasingly automate low-skill translation tasks. Establishment of mentoring, training and certification programs to develop career paths could encourage novices to acquire higher-level skills while they comprehend the work environment of the industry and hone skills toward translation expertise.

Investment in training initiatives and certification programs, as well as increasing the 'professionalisation' of the language industry could accelerate the development of subject matter and 
technical expertise among novice translators. These efforts could be enhanced by close collaboration between university programs in translation studies and translation associations. Such collaborations can foster mentorship programs, internships, and job shadowing opportunities. A case in point is mentoring, which is a cost-effective and feasible approach that could be inculcated via virtual or face-to-face modes. An example of such an existing program is the American Translators Association (ATA) Mentoring Program (ATA 2017). The ATA Mentoring Program pairs volunteering mentors with mentees over a year, both mentors and mentees can be individuals or translation/interpreting companies that share same fields of interest and equivalent goals of the mentoring program. In such mentorship programs it is important to find similarities in areas of specialization, specific business goals, specific language pairs, and certification needs. Mentorship programs could allow a mentee to work with a certified translator to pursue a certification goal, or provide a newcomer an opportunity to learn about the language industry in order to remain competitive. Mentorship could also be provided by language service providers within an organisation by project managers and freelancers. Internships and job shadowing experiences can also allow novices to prepare themselves with multiple applicable skills that can in turn result in intrinsic task satisfaction for novices when they work in the language industry.

In summary, it is crucial to bridge the large satisfaction gap between experts and novices since it is necessary to constantly nurture young professionals in order to develop motivated translators who are committed to building a career in the language industry. Despite the heavy adoption of automation, the language industry is largely dependent on indispensable human capital. As a nascent industry that needs new talent, structured career development and careful management of training programs can be introduced to boost the confidence of novices and accelerate their acquisition of advanced skills that are necessary to be successful in the language industry.

\section{References}

American Translators Association. ATA Mentorship Program [online].

https://www.atanet.org/careers/mentoring.php (accessed 15 December 2017)

Bandura, Albert 1995: Self-Efficacy in Changing Societies. Cambridge: Cambridge University Press.

Biel, Łucja 2011: Professional Realism in the Legal Translation Classroom: Translation Competence and Translator competence. In Meta 56 (1), 162-178.

Biel, Łucja/Sosoni, Vilelmini 2017: The translation of economics and the economics of translation. In Perspectives: Studies in Translatology 25 (3), 351-361.

Boucau, F. 2006: The European Translation Markets. Updated Facts and Figures 2006-2010. Paper presented at the 2nd International Conference of the European Union of Associations of Translation Companies (EUATC), n.p.

Bowker, Lynne 2005: Professional Recognition in the Canadian Translation Industry: How is it Perceived by Translators and Employers? In Translation Watch Quarterly 1, 19-32.

Burke, Ronald J. 2001: Organizational Values, Work Experiences and Satisfaction among Managerial and Professional Women. In Journal of Management Development 20, 346-353.

Burke, Ronald J./ McKeen Carol A. 1995: Work Experiences, Career Development, and Career Success of Managerial and Professional Women. In Journal of Social Behavior and Personality 10(6), 81-96.

Byrne, Jody 2006: Technical Translation: Usability Strategies for Translating Technical Documentation. Dordrecht: Springer.

Chen, Ling-Hsiu 2008: Job satisfaction among information system (IS) personnel. In Computers in Human Behavior 24 (1), 105-118.

Chen, Tser-Yieth/Chang, Pao-Long/Yeh, Ching-Wen 2004: An investigation of career development programs, job satisfaction, professional development and productivity: the case of Taiwan. In Human Resource Development International 7 (4), 441-63.

Chesterman, Andrew/Wagner, Emma 2002: Can Theory Help Translators? A Dialogue between the Ivory Tower and the Wordface, Manchester: St. Jerome.

Dam, Helle V./Zethsen, Karen K. 2010: Translator Status: Helpers and Opponents in the Ongoing Battle of an Emerging Profession. In Target 22 (2), 194-1211. 
Dam, Helle V./Zethsen, Karen K. 2016: "I think it is a wonderful job" On the solidity of the translation profession. In The Journal of Specialised Translation 25, 174-187.

Dam, Helle V./Zethsen, Korning K. 2008: Translator Status. In The Translator 14 (1), 71-96.

DePalma, Donal A./Stewart, Robert G./Lommel, Arle/Pielmeier, Hélène 2017: The language Services Market. Chelmsford, Massachusetts: Common Sense Advisory [online].

https://insights.csa-research.com/reportaction/39815/Marketing (accessed 17 January 2019)

Dörnyei, Zoltan 2007: Research methods in applied linguistics: Quantitative, qualitative, and mixed methodologies. Oxford: Oxford University Press.

Dragsted, Barbara 2005: Segmentation in translation: Differences across levels of expertise and difficulty. In Target 17 (1), 49-70.

Dragsted, Barbara 2006: “Computer-aided Translation as a Distributed Cognitive Task. In Pragmatics \& Cognition 14 (2), 443-464.

Dunne, Keiran J. 2011: Integrating Project Management into Translation Curricula: The Kent State University Experience. In Schmitt Peter A./Herold, Susann/Weilandt Annette (Eds.), Translationsforschung. Tagungsberichte des LICTRA 2010 IX. Leipziger Studien zur angewandten Linguistik und Translatologie, Vol. 1. New York: Peter Lang, 183-195.

Dunne, Keiran J. 2012: The industrialization of translation: Causes, consequences and challenges. In Translation Spaces 1, 143-68.

Durban, Chris 2010: The Prosperous Translator. Raleigh, North Carolina: Lulu.

Ehrensberger-Dow, Maureen /Massey, Gary 2014a: Cognitive ergonomic issues in professional translation. In Schwieter, John/Ferreira, Aline (eds.), The Development of Translation Competence: Theories and Methodologies from Psycholinguistics and Cognitive Science. Newcastle: Cambridge Scholars, 2-57.

Ehrensberger-Dow, Maureen/Massey, Gary 2014b: Translators and machines: Working together. In Man vs. Machine? Vol.1. Proceedings of XXth World Congress of the International Federation of Translators. Berlin: BDÜ Fachverlag, 199-207.

European Union 2006: Court of Editors: concerning translation expenditure incurred by the Commission, the Parliament and the Council together with the Institutions' replies (Report No. 9/2006), Journal of the European Union. [online].

https://www.eca.europa.eu/Lists/ECADocuments/SR06_09/SR06_09_EN.PDF (accessed 20 May 2019)

Garcia, Ignacio 2009: Beyond Translation Memory: Computers and the Professional Translator. In The Journal of Specialised Translation 12, 199-214.

Gouadec, Daniel 2007: Translation as a Profession. Amsterdam: John Benjamins.

Greene, Lloyd/ Burke, George 2007: Beyond self-actualization. In Journal of Health and Human Services Administration 30 (2), 116-128.

Hale, Sandra/Napier, Jemina 2013: Research methods in interpreting: A practical resource. London: Bloomsbury.

Hall, Matthew/Smith, David/Langfield-Smith, Kim 2005: Accountants' Commitment to Their Profession: Multiple Dimensions of Professional Commitment and Opportunities for Future Research. In Behavioral Research in Accounting, 17 (1), 87-96.

Herzberg, Frederick 2003: One more time: How do you motivate employees? In Harvard Business Review 81 (1), 87-96.

Holz-Mänttäri, Justa 1984: Translatorisches Handeln: Theorie Und Methode. Helsinki: Suomalainen Tiedeakatemia.

Ibarra, Herminia 1999: Provisional selves: Experimenting with image and identity in professional adaptation. In Administrative Science Quarterly 44 (4), 764-791.

Jääskeläinen, Riitta 2010: Are all professionals experts? In Shreve, Gregory M./Angelone, Erik (Eds.), Translation and Cognition. Amsterdam: John Benjamins, 213-227.

Kaplan, Stephen 1983: A Model of Person-Environment Compatibility. In Environment and Behavior 15 (3), 311-332.

Katan, David 2009: Translation Theory and Professional Practice: A Global Survey of the Great Divide. In Hermes 42 , $111-153$.

Kelly, Nataly/ Stewart, Robert G. 2010: The Top 35 Language Service Providers. Lowell, MA: Common Sense Advisory.

Kingscott, Geoffrey 2002: Technical Translation and Related Disciplines. In Perspectives: Studies in Translatology 10, $247-255$.

Koriat, Asher 1993: How do we Know that we Know? The Accessibility Model of the Feeling of Knowing. In Psychological Review 100 (4), 609-39. 
Kruger, Justin/Dunning, David 1999: Unskilled, Unaware of it? How Difficulties in Recognizing One's Own Incompetence Lead to Inflated Self-Assessments. In Journal of Personality and Sociology 77 (6), 1121-1134.

Kyndt, Eva/Dochy, Filip/Michielsen, Maya/Moeyaert, Bastiaan 2009: Employee Retention: Organisational and Personal Perspectives. In Vocations and Learning 2 (3), 195-215.

Mason, Claire M./Griffin, Mark A. 2002: Group Task Satisfaction: Applying the Construct of Job Satisfaction to Groups. In Small Group Research 33, 271-312.

Mayer, John D./Salovey, Peter 1993: The Intelligence of Emotional Intelligence. In Intelligence 17 (4), $433-442$.

McKay, Corinne 2006: How to Succeed As a Freelance Translator. New York: Two Rat Press.

Mellinger, Christopher D./Hanson, Thomas A. 2017: Quantitative Research Methods in Translation and Interpreting Studies. London \& New York: Routledge.

Mortensen, Jenny K./Nyland, Nora K./Fullmer, Susan/Eggett, Dennis L. 2002: Professional Involvement is Associated with Increased Job Satisfaction among Dietitians. In Journal of the American Dietetic Association 102 (10), $1452-54$.

Muñoz Martín, Ricardo 2009: Expertise and Environment in Translation. In Mutatis Mutandis 2 (1), 24-37.

Muñoz Martín, Ricardo 2014: Situating Translation Expertise: A Review with a Sketch of a Construct. In Schwieter, John/Ferreira, Aline (eds.), The Development of Translation Competence: Theories and Methodologies from Psycholinguistics and Cognitive Science. Newcastle: Cambridge Scholars, 2-57.

Pan, Li 2014: Investigating institutional practice in news translation: An empirical study of a Chinese agency translating discourse on China. In Perspectives: Studies in Translatology 22 (4), 547-565.

Pym, Anthony/Grin, François/Sfreddo, Claudio/Chan, Andy L. J. 2012: The status of the translation profession in the European Union. Luxembourg: European Commission.

Rodríguez-Castro, Mónica 2015: Conceptual Construct and Empirical Validation of a Multifaceted Instrument for Translator Satisfaction. In The International Journal of Translation and Interpreting Research 7 (2), 30-50.

Rodríguez-Castro, Mónica 2016: Intrinsic and Extrinsic Sources of Translator Satisfaction: An Empirical Study. In Entreculturas 7-8, 195-229. [online]. http://www.entreculturas.uma.es/n7yn8pdf/articulo10.pdf (accessed 20 May 2019).

Shreve, Gregory M./Angelone, Erik/Lacruz, Isabel 2018: Are expertise and translation competence the same? Psychological reality and the theoretical status of competence. In Lacruz, Isabel/Jääskeläinen, Rita (Eds.), Innovation and Expansion in Translation Process Research. Amsterdam/Philadelphia: John Benjamins, 37-54.

Shreve, Gregory M./Angelone, Erik 2010: Translation and Cognition. Amsterdam: John Benjamins.

Shreve, Gregory M. 2002: Knowing Translation: Cognitive and Experiential Aspects of Translation Expertise from the Perspective of Expertise Studies. In Riccardi, Alessandra (Ed.), Translation Studies. Perspectives on an Emerging Discipline. Cambridge: University Press, 150-171.

Shreve, Gregory M. 2006: The Deliberate Practice: Translation and Expertise. In Journal of Translation Studies 9 (1), $27-42$.

Shreve, Gregory M. 2009: Recipient-Orientation and Metacognition in the Translation Process. In Dimitriu, Rodica/ Shlesinger, Miriam (eds.), Translators and their Readers. In Homage to Eugene A. Nida. Brussels: Les Editions du Hasard, 255-270.

Sirén, Seija/Hakkrarainen, Kai 2002: Expertise in Translation. In Across Languages and Cultures 3 (1), 71-82.

Stamps, Paula L. 1997: Nurses and Work Satisfaction: An Index for Measurement. Chicago, IL: Health Administration Press.

Tett, Robert P./Meyer, John P. 1993: Job Satisfaction, Organizational Commitment, Turnover Intention, and Turnover: Path Analyses based on Meta-analytic Findings. In Personnel Psychology 46 (2), 259-293.

Tymoczko, Maria/Ireland, Colin A. 2003: Language and Tradition in Ireland: Continuities and Displacements. Amherst: University of Massachusetts Press.

Woll, Stanley 2001: Memory, reasoning, and judgment in the real world. London/New York: Psychology Press. 


\section{Appendix 1. Questionnaire - Professional Satisfaction Index}

\begin{tabular}{|c|c|c|c|c|c|}
\hline Item & $\begin{array}{l}\text { Very much } \\
\text { agree }\end{array}$ & $\begin{array}{l}\text { Agree } \\
\text { moderately }\end{array}$ & $\begin{array}{l}\text { Neither agree } \\
\text { nor disagree }\end{array}$ & $\begin{array}{l}\text { Disagree } \\
\text { moderately }\end{array}$ & $\begin{array}{l}\text { Very much } \\
\text { disagree }\end{array}$ \\
\hline \multicolumn{6}{|l|}{ I identify strongly with my profession } \\
\hline \multicolumn{6}{|l|}{ I feel unappreciated professionally } \\
\hline \multicolumn{6}{|l|}{ I feel I need to update my skills } \\
\hline \multicolumn{6}{|l|}{ I feel I need more certifications } \\
\hline \multicolumn{6}{|l|}{ Mentoring has been helpful for my career } \\
\hline \multicolumn{6}{|l|}{ I feel I may leave the profession } \\
\hline Item & Very likely & Likely & $\begin{array}{l}\text { Moderately } \\
\text { likely }\end{array}$ & Unlikely & $\begin{array}{l}\text { Very } \\
\text { unlikely }\end{array}$ \\
\hline \multicolumn{6}{|l|}{$\begin{array}{l}\text { How likely is it that you will find a new } \\
\text { job if you leave your current one? }\end{array}$} \\
\hline Item & $\begin{array}{l}\text { Very } \\
\text { satisfied }\end{array}$ & $\begin{array}{l}\text { Somewhat } \\
\text { satisfied }\end{array}$ & $\begin{array}{l}\text { Neither } \\
\text { satisfied nor } \\
\text { dissatisfied }\end{array}$ & $\begin{array}{l}\text { Somewhat } \\
\text { dissatisfied }\end{array}$ & Dissatisfied \\
\hline \multicolumn{6}{|l|}{$\begin{array}{l}\text { Overall satisfaction with your role in the } \\
\text { industry }\end{array}$} \\
\hline \multicolumn{6}{|l|}{$\begin{array}{l}\text { My current role in translation meets my } \\
\text { professional }\end{array}$} \\
\hline \multicolumn{6}{|l|}{ Social recognition of my profession } \\
\hline \multicolumn{6}{|l|}{$\begin{array}{l}\text { Opportunities for skill or career } \\
\text { development }\end{array}$} \\
\hline \multicolumn{6}{|l|}{$\begin{array}{l}\text { My schedule allows me to participate in } \\
\text { professional development initiatives }\end{array}$} \\
\hline \multicolumn{6}{|l|}{ Being involved in prestigious projects } \\
\hline \multicolumn{6}{|l|}{ Presenting at conferences } \\
\hline \multicolumn{6}{|l|}{ Attending conferences } \\
\hline \multicolumn{6}{|l|}{ Presenting training sessions or workshops } \\
\hline \multicolumn{6}{|l|}{ Keeping my current memberships } \\
\hline \multicolumn{6}{|l|}{ Being involved in prestigious clients } \\
\hline \multicolumn{6}{|l|}{$\begin{array}{l}\text { I can afford to choose with whom I work } \\
\text { (e.g. agencies, clients) }\end{array}$} \\
\hline \multicolumn{6}{|l|}{ Flexibility to accept and reject projects } \\
\hline \multicolumn{6}{|l|}{$\begin{array}{l}\text { Generating revenue from my brand } \\
\text { recognition }\end{array}$} \\
\hline $\begin{array}{l}\text { Receiving new projects from a long-term } \\
\text { client }\end{array}$ & & & & & \\
\hline
\end{tabular}


Appendix 2. Questionnaire - Task Satisfaction Index

\begin{tabular}{|c|c|c|c|c|c|}
\hline Item & $\begin{array}{l}\text { Very much } \\
\text { agree }\end{array}$ & $\begin{array}{l}\text { Agree } \\
\text { moderately }\end{array}$ & $\begin{array}{l}\text { Neither agree } \\
\text { nor disagree }\end{array}$ & $\begin{array}{l}\text { Disagree } \\
\text { moderately }\end{array}$ & $\begin{array}{l}\text { Very much } \\
\text { disagree }\end{array}$ \\
\hline \multicolumn{6}{|l|}{$\begin{array}{l}\text { Knowledge of CAT tools is essential to } \\
\text { meet my deadlines }\end{array}$} \\
\hline \multicolumn{6}{|l|}{$\begin{array}{l}\text { I feel that deadlines do not compromise } \\
\text { quality }\end{array}$} \\
\hline \multicolumn{6}{|l|}{$\begin{array}{l}\text { My subject matter expertise helps me } \\
\text { meet deadlines }\end{array}$} \\
\hline \multicolumn{6}{|l|}{$\begin{array}{l}\text { I feel I have a good understanding of task } \\
\text { scope }\end{array}$} \\
\hline Item & $\begin{array}{l}\text { Very } \\
\text { satisfied }\end{array}$ & $\begin{array}{l}\text { Somewhat } \\
\text { satisfied }\end{array}$ & $\begin{array}{l}\text { Neither satisfied } \\
\text { nor dissatisfied }\end{array}$ & $\begin{array}{l}\text { Somewhat } \\
\text { dissatisfied }\end{array}$ & Dissatisfied \\
\hline \multicolumn{6}{|l|}{$\begin{array}{l}\text { Descriptions show accurate nature of the } \\
\text { work to be done }\end{array}$} \\
\hline \multicolumn{6}{|l|}{$\begin{array}{l}\text { My ability to perform a wide variety of } \\
\text { tasks }\end{array}$} \\
\hline \multicolumn{6}{|l|}{ High terminological complexity } \\
\hline \multicolumn{6}{|l|}{$\begin{array}{l}\text { Working on challenging and complex } \\
\text { tasks }\end{array}$} \\
\hline \multicolumn{6}{|l|}{$\begin{array}{l}\text { PM/client shows appreciation for my } \\
\text { work }\end{array}$} \\
\hline \multicolumn{6}{|l|}{$\begin{array}{l}\text { Level of autonomy given to make } \\
\text { decisions }\end{array}$} \\
\hline \multicolumn{6}{|l|}{$\begin{array}{l}\text { Completing a complex project } \\
\text { successfully motivates me }\end{array}$} \\
\hline $\begin{array}{l}\text { Having outstanding offers or projects } \\
\text { motivates me }\end{array}$ & & & & & \\
\hline
\end{tabular}

